\title{
Chemical composition and insecticidal activity of Anacyclus pyrethrum essential oil from the Bensliman area against Culex pipiens
}

\author{
Kawtar El mokhtari ${ }^{1, *}$, M'hammed El kouali ${ }^{1}$, Mohammed Talbi ${ }^{1}$, Latifa Hajji ${ }^{1}$ and \\ Abdelhak EI Brouzi ${ }^{2}$ \\ ${ }^{1}$ Laboratory of Analytical Chemistry and Physical Chemistry of Materials, University Hassan II of Casablanca, \\ Faculty of Sciences Ben M'sik, Casablanca, Morocco \\ ${ }^{2}$ Laboratory of Physical Chemistry and Bioorganic, University Hassan II of Casablanca, Faculty of Sciences and \\ Technology Mohammedia, Morocco
}

\begin{abstract}
Anacyclus pyrethrum is a herbaceous plant that belongs to the Asteraceae family. The focus of the present study is to extract the essential oil from this plant, to determine its chemical composition and to evaluate its insecticidal activity against the larvae of the mosquito Culex pipiens. The essential oil from A. pyrethrum collected from the region of Bensliman in Morocco was extracted by hydrodistillation and analyzed by gas chromatography coupled to mass spectrometry were studied. Essential oil yield obtained by hydrodistillation was $0.09 \%$. The major aroma constituents were Spathulenol (20.47\%), Germacrene D (16.48\%), Caryophyllene oxide (13.20\%), 4(14)-Salviale-1-one (8.27\%) and Caryophyllene 4(14),8(15)-dien-5 $\alpha$-ol (7.30\%). The larvicidal test carried out according to a methodology based on the standard protocol of the World Health Organization was studied on $4^{\text {th }}$ instar larvae of $C$. pipiens and showed that A. pyrethrum essential oil possesses remarkable insecticidal properties. After 24 hours of exposition, larvicidal assays revealed a $100 \%$ mortality of $C$. pipiens larvae. The dose of $40 \mu \mathrm{L} / \mathrm{mL}$ was toxic enough to cause $100 \%$ larval mortality of C. pipiens. The lethal concentrations LC50 and LC90 calculated for the essential oil studied were of the order of $14.79 \mu \mathrm{L} / \mathrm{mL}$ and 19.95 $\mu \mathrm{L} / \mathrm{mL}$, respectively. To control mosquitoes, this essential oil extracted from A. pyrethrum might be used as a natural insecticide and therefore could be an alternative to synthetic insecticides already present on the market.
\end{abstract}

Keywords: Anacyclus pyrethrum; essential oil; hydrodistillation; GC-MS; insecticidal activity; Culex pipiens.

\section{Introduction}

Anacyclus pyrethrum is a perennial plant; this herb reaches 30 to $50 \mathrm{~cm}$ in height. This plant is an endemic species of Algeria and Morocco. It is also harvested for export, especially to the Middle East, India, Algeria and Morocco are the traditional suppliers ${ }^{1}$. Its root is used in traditional medicine. A. pyrethrum is a plant which has interesting therapeutic effects. This plant is commonly featured in medical journals mainly due to the sesquiterpene lactones it contains. Its therapeutic use is mainly due to its antiinflammatory and antimicrobial activity. It is also used in the treatment of liver diseases, in the treatment of rheumatism, sciatica, colds, neuralgia and paralysis ${ }^{2}$. In Algeria (Tlemcen region) this plant can be used for the treatment of diabetes. The root of A. pyrethrum purifies the blood, used to control anemia thanks to its richness in vitamin B12 and Iron. In Morocco, the roots of $A$. pyrethrum are used in traditional medicine to treat various pathologies; in fact, this plant is

*Corresponding author: Kawtar El mokhtari

Email address: kawtarelmokhtari@gmail.com

DOI: http://dx.doi.org/10.13171/mjc101020211198kem widely known for its medicinal properties and especially its efficacy against skin infections, especially fungal infections. Also, infusion of the roots is recommended against toothache and in case of problems related to salivary secretion ${ }^{1}$.

Chemical analysis of $A$. pyrethrum shows that they contain an alkaloid $\mathrm{N}$-isobutylamide, called "pellitorine", and mainly accumulate alkamides of which pellitorine is the major active constituent, they also contain anacycline, enetriyne alcohol, hydrocaroline, inulin and volatile oils which have antibacterial, larvicidal and insecticidal properties. Alkamides are a large and growing group of natural bioactive compounds found in A. pyrethrum. These natural products have a wide range of biological activities: antimicrobial, antiviral, diuretic, antioxidant and analgesic. In addition, alkamides are involved in the potentiation of antibiotics ${ }^{3}$.

Hydrodistillation is the routine method recommended by pharmacopoeias to extract essential oils from plant

Received November 29, 2019

Accepted December 30, 2019

Published January 21, 2020 
materials. The main advantage of this method is due to its simplicity of implementation, its reduced cost and the absence of organic solvent ${ }^{4-9}$.

The extracted essential oils are analyzed by different techniques; the most used is high-performance liquid chromatography (HPLC) ${ }^{10-13}$ and thin layer chromatography (TLC). However, due to the high volatility of the compounds, the most appropriate technique is gas chromatography (GC); in addition, the most accurate information in qualitative analysis is obtained by gas chromatography coupled with mass spectrometry (GC-MS) ${ }^{14}$.

Mosquitoes are among the vectors of many vectorborne diseases. The species $C$. pipiens is the most common mosquito in the world that is responsible for the transmission of parasitic diseases ${ }^{15}$ and its impact on human health is very significant. $C$. pipiens was responsible for the transmission of several epidemics that affected Morocco in $2003{ }^{15}$ and $2010^{16}$. The mosquito population control generally involves the use of synthetic chemical products; however, the use of these products caused adverse effects to humans and the environment ${ }^{17}$.

For this reason, synthetic chemicals have been replaced by insecticides based on natural products extracted from plants. For this, we contributed to our part, to finding other natural substances that are alternative and harmless to the environment for mosquitoes control.

In this context, our study aims to extract A. pyrethrum's essential oil, to identify its chemical composition in order to highlight the specific compounds of this oil; also, we sought to assess the larvicidal potential of this essential oil as a botanical insecticide for the control of mosquitos' larvae mainly the larvae of $C$. pipiens which is a public health problem worldwide.

\section{Experimental section}

\subsection{Materials}

The plant was cultivated in the region of Benslimane in Morocco: (Latitude: 33 $42^{\prime} 6^{\prime}$ ' $\mathrm{N}$; Longitude: $7^{\circ} 11^{\prime} 8$ ' W; Altitude: $233 \mathrm{~m}$ ). The climate is humid with an annual average temperature of $23.7^{\circ} \mathrm{C}$. The vegetal product was harvested during the flowering stage in May 2019. After collection, the plant was airdried at room temperature $\left(25^{\circ} \mathrm{C}\right)$ for 20 days.

\subsection{Extraction procedure}

Dried leaves, stems and roots, were hydro-distilled on a Clevenger-type apparatus for three hours. Preliminary tests revealed that three hours of the distillation of the plant studied is the optimum period which allows obtaining a good yield. The plant material $(300 \mathrm{~g})$ was placed in a $5 \mathrm{~L}$ round-bottom flask with $3 \mathrm{~L}$ distilled water. After this, the essential oil was recovered by a syringe, then; this oil was dried over anhydrous sodium sulfate, filtered, and stored in a sealed vial at $4^{\circ} \mathrm{C}$ for subsequent analyses, in order to avoid any alteration of the essence before chromatographic analysis.

\subsection{GC-MS analysis}

The extracted essential oil was analyzed by gas chromatography coupled with mass spectrometry (GC-MS). The profile of volatile compounds was characterized by gas chromatography (GC) (Agilent 7890A Series) coupled to mass spectrometry (MS) equipped with a multimode injector and a 123-BD11 column with dimensions $15 \mathrm{~m} \times 320 \mu \mathrm{m} \times 0,1 \mu \mathrm{m}$ and the injected volume was $4 \mu 1$.

The soluble extract was injected into the column in $1 / 4$ split mode using helium as carrier gas at $3 \mathrm{~mL} \cdot \mathrm{min}^{-1}$. The ion source and quadrupole temperatures were 230 and $150^{\circ} \mathrm{C}$, respectively. The oven temperature program was initially programmed at $30^{\circ} \mathrm{C}$ for $5 \mathrm{~min}$ and was programmed to increase at a rate of $4^{\circ} \mathrm{C} / \mathrm{min}$ until it reached $360^{\circ} \mathrm{C}$. The identification of the components was done using NIST 2014 MS Library.

\subsection{Larvae}

The larvae of the mosquito $C$. pipiens subjected to the insecticide test were collected from a permanent larval shelter located at Mohammedia in Morocco. This study area is located north-east of Oued N'fifikh (latitude $33^{\circ} 43^{\prime} 12$ "N and longitude $72^{\circ} 20$ ' 24 "W). This zone is characterized by its humidity. This humidity is a source of proliferation of mosquito larvae which are harmful to the population, and it is characterized by a very high density of the species $C$. pipiens.

The collection of larvae was carried out by using a rectangular plastic tray, which was introduced into the water by tilting at $45^{\circ}$ to the water surface. After the harvest, the larvae were identified with a binocular microscope. The identification was carried out based on their morphological characters. The first instar larvae of $C$. pipiens harvested placed in rectangular trays and kept in rearing in these trays filled with water and were maintained continuously at a temperature between 25 and $27^{\circ} \mathrm{C}$ in $(70 \% \pm 2 \%)$ relative humidity. The larvae were fed on fish food and water was renewed every two days ${ }^{18}$. After 6 to 8 days, we obtained $4^{\text {th }}$ instar larvae which were used in larvicidal tests.

\subsection{Larvicidal assay}

The insecticidal tests were carried out according to the standard protocol of the World Health Organization (1985). A solution containing acetone with different doses of A. pyrethrum essential oil (5, 10, 15, 20 and $40 \mu \mathrm{L} / \mathrm{mL}$ of acetone) was prepared. Preliminary experiments made it possible to select these doses. 1 $\mathrm{ml}$ of each prepared solution is placed in a beaker containing $99 \mathrm{ml}$ of distilled water in contact with 20 C. pipiens larvae of $4^{\text {th }}$ instar; the same number of larvae was placed in a control beaker containing $99 \mathrm{ml}$ of distilled water and $1 \mathrm{ml}$ of acetone. 
The beakers were placed in a laboratory room under the temperature conditions $\left(27^{\circ} \mathrm{C} \pm 2{ }^{\circ} \mathrm{C}\right)$ and humidity of $(70 \% \pm 2 \%)$. Five repetitions were performed for each dose as well as for the control. After one day of contact, we counted the dead larvae. Corrected mortality for treated larvae is expressed according to Abbott's formula ${ }^{19}$ :

$M \%=\frac{M_{o}-M_{c}}{100-M_{c}} \times 100$

M: Corrected mortality

Mo: Mortality observed in larvae

Mc: Mortality observed in control

\subsection{Statistical analysis}

In order to assess the efficacy of the toxicity of A. pyrethrum's essential oil, we calculated LC50 and LC90, defined as the lethal concentrations causing respectively $50 \%$ and $90 \%$ mortality in the population of larvae of $C$. pipiens treated. These values were determined by probit analysis, according to Finney.

\section{Results and discussions}

\subsection{Essential oil yield}

The essential oil extracted from A. pyrethrum is characterized by its orange color. For calculations of essential oil yield, three replicates were performed for plant material. This yield was $0.09 \%$, which is slightly higher than that found by Elazzouzi ${ }^{20}$, which was around $0.07 \%$ for the A. pyrethrum essential oil from the Timahdite region. Moreover, this yield is higher than that found in Algeria ${ }^{1}$, which was $0.019 \%$.

However, only some studies report on the performance of $A$. pyrethrum's essential oil. This oil yield is relatively low $(<1 \%)$ for all the studies carried out on this plant. Many factors can influence the yield of an essential oil, such as environmental conditions, extraction technique, drying, the harvesting period of the plant; this period constitutes a parameter that influences both the chemical yield and quality of the essential oil, as well as the harvesting environment and the age of the plant material ${ }^{21-24}$.

Similarly, after harvesting, the biosynthetic activity is reduced, which would lead to a drop in the production of essential oil in the plant material ${ }^{7}$. This plant has a considerable advantage thanks to the essential larvicidal power of its essential oil which was proved against mosquito larvae; it can, therefore, be said that the essential oil of $A$. pyrethrum is a candidate for the development of new botanical insecticides applied against the mosquito. As a result, it has become required to highlight research for the optimization and improvement of the yield of the essential oil extracted.

The increase in essential oil yield can be attributed to several important factors, including the production of essential oil, stimulated or modified using environmental triggers, including nutritional changes. Several studies have reported the effects of agricultural practices on secondary metabolites in plants. The mineral amendments contribute to the increase in plant mass and therefore, to the increase in the yield of essential oil without affecting the composition of this oil. The use of nitrogen fertilizers has produced the best effects concerning the yield and production of essential oil in Origanum vulgare $L^{25}$.

Similarly, an increase in the fertilizer rate in the cultivation of chamomile (Chamaemelum nobile L) results in an increase in essential oil content but does not change its composition. Also, the essential oil yield can be increased by applying elicitors which have a role in activating genes to stimulate the production of secondary metabolites in plants ${ }^{26}$.

\subsection{Chemical composition}

Analyses of the essential oil revealed the presence of 32 compounds. These compounds represent about $92.67 \%$ of the total chemical composition. The results obtained are shown in Table 1.

Table 1. Chemical composition of the essential oil of A. pyrethrum of Benslimane

\begin{tabular}{|c|c|c|c|c|}
\hline KI & Compound & Molecular mass & $\begin{array}{c}\text { Molecular } \\
\text { formula }\end{array}$ & Percentage (\%) \\
\hline $\mathbf{7 7 0}$ & Hexanal & 100 & $\mathrm{C}_{6} \mathrm{H}_{12} \mathrm{O}$ & 0.03 \\
\hline $\mathbf{9 3 0}$ & $\alpha$-Pinene & 136 & $\mathrm{C}_{10} \mathrm{H}_{16}$ & 0.63 \\
\hline $\mathbf{9 4 4}$ & Camphene & 136 & $\mathrm{C}_{10} \mathrm{H}_{16}$ & 2.30 \\
\hline $\mathbf{9 7 1}$ & $\beta$-Pinene & 136 & $\mathrm{C}_{10} \mathrm{H}_{16}$ & 0.56 \\
\hline $\mathbf{9 7 8}$ & Myrcene & 136 & $\mathrm{C}_{10} \mathrm{H}_{16}$ & 0.72 \\
\hline $\mathbf{1 0 1 1}$ & p-Cymene & 134 & $\mathrm{C}_{10} \mathrm{H}_{14}$ & 0.50 \\
\hline $\mathbf{1 0 2 1}$ & Limonene & 136 & $\mathrm{C}_{10} \mathrm{H}_{16}$ & 0.05 \\
\hline $\mathbf{1 0 8 0}$ & Linalool & 154 & $\mathrm{C}_{10} \mathrm{H}_{18} \mathrm{O}$ & 0.1 \\
\hline $\mathbf{1 0 8 3}$ & Nonanol & 144 & $\mathrm{C}_{9} \mathrm{H}_{20} \mathrm{O}$ & 0.40 \\
\hline $\mathbf{1 1 7 5}$ & Estragol & 148 & $\mathrm{C}_{10} \mathrm{H}_{12} \mathrm{O}$ & 0.15 \\
\hline
\end{tabular}




\begin{tabular}{|c|c|c|c|c|}
\hline 1178 & $\alpha$-Terpineol & 154 & $\mathrm{C}_{10} \mathrm{H}_{18} \mathrm{O}$ & 0.02 \\
\hline 1263 & E-Anethole & 148 & $\mathrm{C}_{10} \mathrm{H}_{12} \mathrm{O}$ & 0.29 \\
\hline 1267 & Thymol & 150 & $\mathrm{C}_{10} \mathrm{H}_{14} \mathrm{O}$ & 0.01 \\
\hline 1268 & Bornyl Acetate & 196 & $\mathrm{C}_{12} \mathrm{H}_{20} \mathrm{O}_{2}$ & 0.07 \\
\hline 1277 & Carvacrol & 150 & $\mathrm{C}_{10} \mathrm{H}_{14} \mathrm{O}$ & 1.35 \\
\hline 1342 & Nerylacetate & 196 & $\mathrm{C}_{12} \mathrm{H}_{20} \mathrm{O}_{2}$ & 0.06 \\
\hline 1428 & Geranylacetone & 194 & $\mathrm{C}_{13} \mathrm{H}_{22} \mathrm{O}$ & 0.08 \\
\hline 1448 & (E)- $\beta$-Fernesene & 204 & $\mathrm{C}_{15} \mathrm{H}_{24}$ & 0.62 \\
\hline 1457 & $\beta$-Humulene & 204 & $\mathrm{C}_{15} \mathrm{H}_{24}$ & 0.91 \\
\hline 1471 & $\gamma$-Murolene & 204 & $\mathrm{C}_{15} \mathrm{H}_{24}$ & 4.20 \\
\hline 1480 & Germacrene D & 204 & $\mathrm{C}_{15} \mathrm{H}_{24}$ & 16.48 \\
\hline 1500 & b-Bisabolene & 204 & $\mathrm{C}_{15} \mathrm{H}_{24}$ & 1.98 \\
\hline 1509 & Cubebol & 222 & $\mathrm{C}_{15} \mathrm{H}_{26} \mathrm{O}$ & 4.01 \\
\hline 1554 & $\begin{array}{c}\text { cis-3- } \\
\text { Hexenylbenzoate }\end{array}$ & 204 & $\mathrm{C}_{13} \mathrm{H}_{16} \mathrm{O}_{2}$ & 0.04 \\
\hline 1557 & Spathulenol & 220 & $\mathrm{C}_{15} \mathrm{H}_{24} \mathrm{O}$ & 20.47 \\
\hline 1576 & $\begin{array}{c}\text { Caryophyllene } \\
\text { oxide }\end{array}$ & 220 & $\mathrm{C}_{15} \mathrm{H}_{24} \mathrm{O}$ & 13.20 \\
\hline 1578 & $\begin{array}{l}\text { 4(14)-Salviale-1- } \\
\text { one }\end{array}$ & 220 & $\mathrm{C}_{15} \mathrm{H}_{24} \mathrm{O}$ & 8.27 \\
\hline 1626 & $\begin{array}{l}\text { Caryophyllene- } \\
\text { 4(14),8(15)- } \\
\text { dien-5 } \alpha \text {-ol }\end{array}$ & 220 & $\mathrm{C}_{15} \mathrm{H}_{24} \mathrm{O}$ & 7.30 \\
\hline 1641 & Vulgarone-beta & 218 & $\mathrm{C}_{15} \mathrm{H}_{22} \mathrm{O}$ & 1.22 \\
\hline 1645 & $\alpha$-Cadinol & 222 & $\mathrm{C}_{15} \mathrm{H}_{26} \mathrm{O}$ & 2.28 \\
\hline 1668 & $\alpha$-Bisabolol & 222 & $\mathrm{C}_{15} \mathrm{H}_{26} \mathrm{O}$ & 2.21 \\
\hline 1835 & Phytone & 269 & $\mathrm{C}_{18} \mathrm{H}_{36} \mathrm{O}$ & 2.16 \\
\hline \multicolumn{4}{|l|}{ Total } & 92.67 \\
\hline
\end{tabular}

KI: Kovats Index

Oxygenated sesquiterpenes were found to be predominant in the chemical composition identified for A. pyrethrum essential oil studied (58.96\%), followed by the hydrocarbon sesquiterpenes $(24.19 \%)$. Also, the study carried out by Selle ${ }^{1}$ in Algeria on the $A$. pyrethrum showed that the oxygenated sesquiterpenes also represent the most abundant group in the chemical composition of the essential oil with a percentage rises from $37.1 \%$ to $58.6 \%$ respectively before and after flowering. Similarly, in Morocco the study carried out by Elazzouzi 20 showed that the oxygenated sesquiterpenes were the most abundant group in the composition of the essential oil of $A$. pyrethrum harvested from the Timahdite region with a percentage rises from $89.17 \%$ in April to $90.58 \%$ in June.
According to the results of GC-MS analysis of A. pyrethrum essential oil harvested from the Bensliman area, the most abundant compounds were: Spathulenol (20.47\%), Germacrene D (16.48\%), Caryophyllene oxide (13.20\%), 4(14) -Salvial-1-one $(8.27 \%)$ and Caryophyllene- 4(14),8(15) -dien-5 $\alpha$-ol $(7.30 \%)$.

However, other compounds exist in relatively small percentages: $\gamma$-Murolene $(4.20 \%)$, cubebol $(4.01 \%)$, Camphene $(2.30 \%), \alpha$-cadinol $(2.28 \%), \alpha$-Bisabolol (2.21\%), Phytone (2.16\%), b-Bisabolene (1.98\%) and Carvacrol (1.35\%).

Similarly, in Morocco, spathulenol was the most abundant compound with a percentage of (16.90\%), as showed by Zair ${ }^{27}$, and $(13.31 \%)$ as reported by Elazzouzi ${ }^{20}$ for $A$. pyrethrum collected from the 
Meknes region with a relatively small percentage than our essential oil, which is more abundant in spathulenol (20.47\%).

The same species in Ifrane (Morocco); Remok et al. ${ }^{28}$, contain two significant compounds which are spathulenol (16.9\%) and Germacra-4 (15\%).

The study carried out by Selles ${ }^{1}$ on the essential oil of A. pyrethrum in Algeria revealed the presence of 87 compounds of which Germacrene D (13.4\%) is the most abundant. Our oil also contains this compound but with a relatively high percentage $(16.48 \%)$.

According to the results obtained, slight variations are observed in the chemical composition of the A. pyrethrum essential oil collected from different regions. These differences can be explained by factors such as soil and weather conditions, also the extraction method and the drying of the material previous extraction ${ }^{29-35}$. However, spathulenol and germacrene $\mathrm{D}$ are compounds known for their insecticidal activity; which makes the essential oil of A. pyrethrum an excellent natural insecticide. Despite the low yield of essential oil of A. pyrethrum, it was chosen for larvicidal tests; this is due to its chemical composition rich in compounds known for their insecticidal activity.

\subsection{Insecticidal activity of Anacyclus pyrethrum essential oil on the larvae of Culex pipiens}

Analysis of the results of the larvicidal assay (Figure 1) of the essential oil showed that total mortality (100\%) of C. pipiens larvae was found at a dose of $40 \mu \mathrm{L} / \mathrm{mL}$. For control, no mortality was recorded. This activity can be explained by the effect of the majority compounds and can also be due to the activity of individual minor constituents or to the synergistic effect between the several constituents. In a general way, the essential oil is a mixture of several compounds; thus, the active compounds contained in this oil which have for example insecticidal activity can have different mechanisms of action against insects. Indeed, synergistic effects between these active compounds have been observed in various studies ${ }^{36}$. In a previous study on larvicidal activity against the larvae of Spodoptera littoralis, Pavela determined the efficacy of 30 aromatic compounds and their binary combinations which showed a significant synergistic effect on the mortality of S. littoralis. Generally, each compound contained in essential oils is unique in terms of structure and biological activity. Thus various individual substances can in their combinations with other substances provide a significant increase in the effectiveness of essential oil ${ }^{37}$. Therefore; the synergistic relationships between the substances contained in the essential oil have an essential role in terms of insecticidal efficacy.
Indeed, this oil is characterized by a high content of spathulenol (20.47\%), known for its insecticidal properties ${ }^{1}$. A. pyrethrum essential oil contains other major compounds of which Germacrene D (16.48\%) which has significant insecticidal properties. Also, caryophyllene and its derivatives are widely known for their insecticidal, repellent and attractive properties against insects ${ }^{1}$. The presence of these main compounds, in particular, spathulenol (13.5\%) and caryophyllene oxide (14.2\%) was also noticed in the essential oil extracted from E. tereticornis in Benin and which showed significant insecticidal activity against A. gambiae which is a vector of malaria ${ }^{38}$. As well, the essential oils extracted in Chile, obtained by hydrodistillation from the leaves of $H$. foliosusle and B. ambrosoides were very rich in caryophyllene $(3.97 \%)$ and germacrene D $(8.81 \%)$ respectively. These oils proved also significant insecticidal properties against the housefly Musca domestica ${ }^{39}$. Also, the essential oil extracted from G. blepharophylla proved very useful insecticidal activity against Aedes aegypti; therefore, GC-MS analyzes confirmed that essential oil of this plant was rich in caryophyllene oxide $(70 \%){ }^{40}$.

The present study describes for the first time, insecticidal activity of this oil against $C$. pipiens mosquito species. The nature of the chemical composition of this oil as well as the interesting larvicidal results obtained against the larvae of C. pipiens confirm its use as a natural insecticide.

Thus, for the practical application of A. pyrethrum essential oil as a new botanical insecticide, studies on the stability of this essential oil are needed, especially the post-application temperature which can have a significant impact on the efficacy of botanical insecticides based on essential oils ${ }^{41}$. In a previous study carried out by Pavela ${ }^{41}$ on the larvicidal activity of Pimpinella animus's essential oil against $3^{\text {rd }}$ instar larvae of Culex quinquefasciatus, it was found that the temperature has a significant effect on the larvicidal efficacy of the essential oil and it was found that the highest mortality was achieved at high temperatures.

Another study was carried out by the same author concerning the effect of the post-application temperature on the insecticidal efficacy of the essential oil of Thymus vulgaris $L$, applied at different environmental temperatures $\left(15 ; 20 ; 25\right.$ and $\left.30 \pm 1^{\circ} \mathrm{C}\right)$ on the larvae of the Egyptian cotton leafworm Spodoptera littoralis boisd (Lepidoptera: Noctuidae) and on the larvae of Culex quinquefasciatus say. When the essential oil was topically applied against the larvae of $S$. littoralis, the insecticidal efficacy increased with temperature. However, the opposite effect was observed when the oil was applied in the water against $C$. quinquefasciatus larvae. Water at the lower temperature achieved higher mortality of the C. quinquefasciatus larvae ${ }^{36}$. 


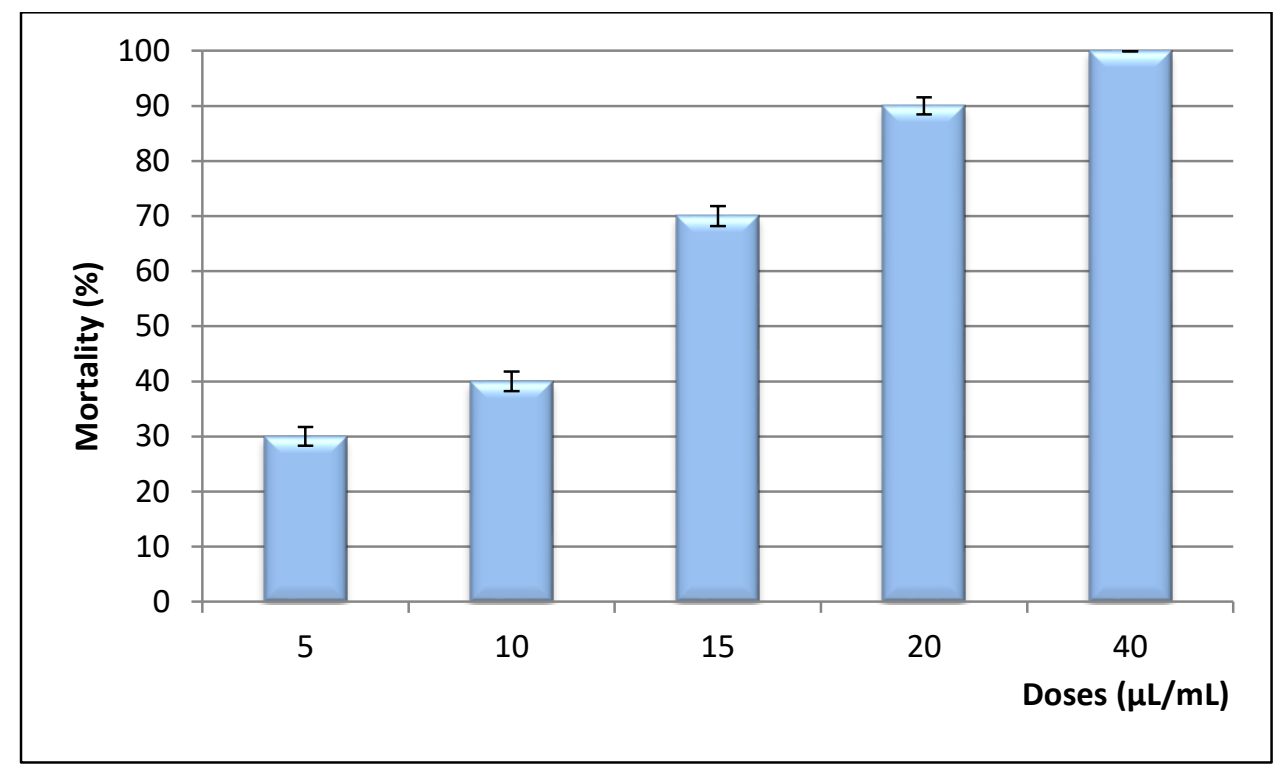

Figure 1. Larvicidal activity of the essential oil of A. pyrethrum against $C$. pipiens

\subsection{Lethal concentrations $\mathrm{LC50}$ and $\mathrm{LC} 90$}

Table 2 shows the values obtained for the lethal concentrations LC50 and LC90. The LC50 and LC90 values recorded for the essential oil of A. pyrethrum are around $14.79 \mu \mathrm{L} / \mathrm{mL}$ and $19.95 \mu \mathrm{L} / \mathrm{mL}$, respectively.

Table 2. Toxicity parameters of A. pyrethrum essential oil against mosquito larvae of $C$. pipiens

\begin{tabular}{|c|c|}
\hline $\mathbf{L C 5 0}(\boldsymbol{\mu L} / \mathbf{m L})[\mathbf{C I} \mathbf{I s}]$ & $\mathbf{L C 9 0}(\boldsymbol{\mu L} / \mathbf{m L})[\mathbf{C I} \mathbf{9 5}]$ \\
\hline $\mathbf{1 4 . 7 9}[\mathbf{1 1 . 9 6 - 1 6 . 7 6}]$ & $19.95[15.05-29.10]$ \\
\hline
\end{tabular}

$\mathrm{CI}_{95}$ : 95\% confidence interval

In the literature, we have not found any authors who have evaluated the larvicidal action of $A$. pyrethrum essential oil on $C$. pipiens. We have, therefore in this work, compared the toxicity of other oils on the species C. pipiens. For this, other essential oil of Kelussia odoratissima Mozaffarian against $C$. pipiens showed a significant effect with an LC50 value of $2.69 \mathrm{ppm}(2.69 \mu \mathrm{L} / \mathrm{L})$ and an LC90 of $7.90 \mathrm{ppm}(7.90$ $\mu \mathrm{L} / \mathrm{L})^{42}$. According to El Ouali Lalami ${ }^{17}$, the essential oil obtained from Thymus vulgaris cultivated in Morocco has been tested for the mortality of the larvae of mosquito's C. pipiens. This oil was found useful at an LC50 of $102.027 \mathrm{ppm}(102.027 \mu \mathrm{L} / \mathrm{L})$ and an LC90 of $179.186 \mathrm{ppm}(179.186 \mu \mathrm{L} / \mathrm{L})$.

Also, the essential oils of Citrus aurantium and Citrus sinensis tested on $C$. pipiens mosquitoes were effective. The calculated LC50 and LC90 of Citrus aurantium and Citrus sinensis were around 139.48 ppm $(139.48 \mu \mathrm{L} / \mathrm{L})$ and $280 \mathrm{ppm}(280 \mu \mathrm{L} / \mathrm{L})$ and of $212.04 \mathrm{ppm}(212.04 \mu \mathrm{L} / \mathrm{L})$ and $516 \mathrm{ppm}(516 \mu \mathrm{L} / \mathrm{L})$, respectively ${ }^{15}$.

Similarly, Tine-Djebbar evaluated the larvicidal activity of the essential oil of Ocimum basilicum on mosquitoes $C$. pipiens, and the values of lethal concentrations LC50 and LC90 were respectively $73.45 \mathrm{ppm}(73.45 \mu \mathrm{L} / \mathrm{L})$ and $101.20 \mathrm{ppm}(101.20 \mu \mathrm{L}$ /L) ${ }^{43}$. Also, we compared the toxicity with other essential oils containing the same majority compounds as our oil. In a previous study on the biological activity of salvia essential oil against two species of mosquitoes, it was reported that caryophyllene oxide and spathulenol were the majority compounds. This oil proved significant larvicidal activity against larvae of Anopheles quadrimaculatus and Aedes aegypti mosquitoes and showed significant toxicity with an LC50 of $6.2 \mathrm{ppm}$ $(6.2 \mu \mathrm{L} / \mathrm{L})^{44}$. Another study showed that Pinus kesiya leaf's essential oil was rich in germacrene D as a majority compound and proved a significant larvicidal activity against the mosquito larvae of Anopheles stephensi, Aedes aegypti and Culex quinquefasciatus with an LC50 of $52 \mu \mathrm{g} / \mathrm{mL}(52 \mathrm{ppm}), 57 \mu \mathrm{g} / \mathrm{mL}$ $(57 \mathrm{ppm})$ and $62 \mu \mathrm{g} / \mathrm{mL}(62 \mathrm{ppm})$ respectively ${ }^{45}$.

The results that we found indicate that $A$. pyrethrum's essential oil has an excellent larvicidal potential against the larvae of $C$. pipiens due to the percentage of mortality, the LC50 and LC90 recorded. For this, we can consider that this oil may be used for mosquito control as a botanical insecticide in the future.

Recent studies have also considered the sublethal effects of essential oils on several critical biological characteristics of insects. A sublethal concentration is defined as inducing no apparent mortality in the experimental population but causes biological, physiological, demographic or behavioral effects on individuals exposed to this concentration. In general, 
the concentration below lethal concentration (LC50) is considered to be sublethal ${ }^{46}$. Sublethal effects can be manifested by reductions in life span, development rates, population growth, fertility, deformities and behavioral changes ${ }^{46}$. Several studies report the sublethal effects of essential oils and their compounds on the biology of insects. The essential oils of Eucalyptus staigeriana, Ocimum gratissimum and Foeniculum vulgare demonstrated several sublethal effects on the biology of $S$. frugiperda by reducing larval and pupal weights in the sublethal concentrations of LC10, LC20 and LC40 ${ }^{45}$. Also, the essential oils of $A$. khorassanica and A. sieberi demonstrated several sublethal effects on the biology of $S$. cerealella at LC30. Indeed, the parameters of the adult life cycle, such as the longevity of females and males and fertility have considerably reduced in the insect treated ${ }^{47}$. For future works, it is also essential to target a broader perspective on the effect of sublethal concentrations of essential oils on the life cycle of insects.

\section{Conclusion}

The essential oil of $A$. pyrethrum containing spathulenol, germacrene $\mathrm{d}$, caryophyllene oxide, 4(14)-Salvial-1-one and caryophyllene-4(14), 8(15)dien- $5 \alpha$-ol as major compounds showed an interesting insecticidal activity against the larvae of the $C$. pipiens. Due to the exciting results that we have obtained, investigations should be conducted on the insecticidal activity of this essential oil to optimize its use as a bioinsecticide. In prospects of this work, we look to evaluate the insecticidal activity of this essential oil on other mosquito species as well to test the insecticidal activity of the aqueous extracts of this plant.

\section{Conflict of interest}

The authors declare that they have no conflict of interest.

\section{References}

1- C. Selles, M. Diba, N. Djaboua, F. Beddoub, A. Musellic, B. Tabtia, G. Costac, B. Hammouti, Antimicrobial activity and evolution of the composition of essential oil from Algerian Anacyclus pyrethrum $L$. through the vegetative cycle, Nat Prod Res., 2013, 27(23), 2231-2234.

2- A. Daoudi, L. Nassiri, J. Ibijbijen, A. Boukil, Ethnobotanical study of pyrethrum «Anacyclus pyrethrum L. » in Meknès, El Hajeb, Khénifra Azrou and Ifrane (Morocco), ScienceLib., 2015, 6(140504), 1-27.

3- H. Elazzouzi, S. Khennouchi, A. Bentayeb, F. Elhilali, T. Zair, Biocidal effects of alkaloids extracted from Anacyclus pyrethrum $L$. (Asteraceae) on Callosobruchus maculatus (Fab.) (Coleoptera: Bruchidae), J Innovation and Applied Studies, 2015, 13(4), 756-774.

4- I.K. Cvetkovikj, N. Cheliku, G. Stefkov,
N. Karapandzova, N. Bardhi, B. Qjazimi, S. Kulevanova, Essential oil composition of five basil cultivars (Ocimum basilicum) from Albania, Mac Pharm Bull., 2015, 61(2),11 - 18.

5- A.S. Ilic, M.P. Antic, S.C. Jelacic, T.M. Solevic, Chemical composition of the essential oils of three Ocimum basilicum L. cultivars from Serbia, Not Bot Horti Agrobo, 2019,47(2), 347-351.

6- M. Ozcan, C.J. Clause, Essential oil composition of Ocimum basilicum L. and Ocimum minimum L. in Turkey, J Food Sci., 2002, 20(6), 223-228.

7- C. Dabire, H.C. Roger, A.B. Nebie, M. Nacro, $\mathrm{S}$. Faustin, Effet du séchage de la matière végétale sur la composition chimique de l'huile essentielle et l'activité antioxydante d'extraits de Ocimum basilicum L, Int J Biol Chem Sci., 2011, 5(3), 1082-1095.

8- T. Taechowisan, J. Jantiya, N. Mungchukeatsakul, S. Waya, P. Phutdhawong, Major Compounds from Ocimum basilicum $L$. and their antimicrobial activity against methicillin-resistant Staphylococcus aureus, J Scientific Technical Research, 2018, 3(3), 3315-3323.

9- D. Benedec, I. Oniga, R. Oprean, M. Tamas, Chemical composition of the essential oils of ocimum basilicum L. cultivated in Romania, Farmacia, 2008, 57(5), 625-629.

10-A. Yahya Al-Maskria, M. Asif Hanifa, M. Yahya Al-Maskarib, A. Susan Abrahama, J. Nasser Al-sabahic, O. Al-Mantheria, Essential Oil from Ocimum basilicum (Omani Basil): A Desert Crop, Nat Prod Commun., 2011, 6(10), 1487-1490.

11-S. Ngom, F. Dieng, M. Diop, Composition chimique et propriétés physico-chimiques des huiles essentielles d'Ocimum basilicum et d'Hyptis suaveolens (L.) Poit. Récoltés dans la région de Dakar au Sénégal, Bull Soc R Sci Liège., 2012, 81, 166-175.

12-S. Joo Lee, K. Umano, T. Shibamoto, K. Geun Lee, Identification of volatile components in basil (Ocimum basilicum L.) and thyme leaves (Thymus vulgaris L.) and their antioxidant properties, Food Chem., 2004, 91(1), 131-137.

13-M. Loredana Soran, S. Codruta Cobzac, C. Varodi, I. Lung, E. Surducan, V. Surducan, The extraction and chromatographic determination of the essentials oils from Ocimum basilicum $L$ by different techniques, Physics, 2009, 182, 12-16.

14-H.O. Elansary, K. Yessoufou, S. Shokralla, K. Mahmoud, S. Skalicka, Enhancing mint and basil oil composition and antibacterial activity using seaweed extracts, Ind Crop Prod., 2016, 92, 50-56.

15-A. El Ouali Lalami, F. EL-Akhal, R. Guemmouh, H. Greche, Valorization as a bio-insecticide of essential oils of Citrus sinensis and Citrus aurantium cultivated in center of Morocco, J. Mater Environ Sci., 2014, 5 (S1), 2319-2324. 
16-B. Aouinty, S. Oufara, F. Mellouki, S. Mahari, Évaluation préliminaire de l'activité larvicide des extraits aqueux des feuilles du ricin (Ricinus communis L.) et du bois de thuya (Tetraclinis articulata (Vahl) Mast.) sur les larves de quatre moustiques culicidés : Culex pipiens (Linné), Aedes caspius (Pallas), Culiseta longiareolata (Aitken) et Anopheles maculipennis (Meigen), J. Biotechnol Agron Soc Environ., 2006, 10(2), 67-71.

17-A. El Ouali Lalami, F. El-Akhal, H. Greche, F. Ouazzani, R. Chahdi, A. Guemmouh, Chemical composition and larvicidal activity of Culex pipiens essential oil of Thymus vulgaris grown in Morocco, J Mater Environ Sci., 2015, 6(1), 214-219.

18-P.A. Ntonga, P. Belong, E.M. Bakwo, G.A. Dadji, J.L. Tamesse, Chemical composition and residue activities of Ocimum canum sims and Ocimum basilicum $L$ essential oils on adult female Anopheles funestus ss, J Anim Plant Sci., 2013,19(1), 2854-2863.

19-A. Ndomo, A.L. Tapondjou, F. Tendonkeng, F.M. Tchouanguep, Evaluation des propriétés insecticides des feuilles de Callistemon viminalis (Myrtaceae) contre les adultes d'Acanthoscelides obtectus (Say) (Coleoptera; Bruchidae), Tropicultura, 2009, 27(3), 137-143.

20-H. Elazzouzi, A. Soro, F. Elhilali, A. Bentayeb, M. Alaoui, M. El Belghiti, T. Zair, Phytochemical study of Anacyclus pyrethrum (L.) of Middle Atlas (Morocco) and in vitro study of antibacterial activity of pyrethrum, Adv in Nat Appl Sci., 2014, 8(8), 31-140.

21-M. Aberchane, M. Fechtal, A. Chaouch, T. Bouayoune, Influence of the duration and the extraction technique on the yield and quality of the essential oils of Atlas cedar (Cedrusatlantica manetti), Ann For Res., 2010, 34, 110-118.

22-M. Bourkhiss, M. Ouhssine, A. Chaouch, B. Satrani, Effet de séchage sur la teneur et la composition chimique des huiles essentielles de Tetraclinis articulata (Vahl) Masters, Agrosolutions, 2009, 20(1), 1-4.

23-O.O. Okoh, A. Sadimenko, A.J. An, The Effects of Age on the Yield and Composition of the Essential Oils of Calendula officinalis, J Applied Sci., 2007, 7, 3806-3810.

24-M. Bourkhiss, M. Hnach, T. Lakhlifi, A. Boughdad, A. Farah, B. Satrani, Effect of Age and Vegetative Stage on the Content and Chemical Composition of Essential Oils of Thuja Articulata, Technologies de Laboratoire, 2011, 6(23), 64-68.

25-S. Al Ahl, H.A.H. Hasnaa, S.A. Hendawy, Effect of potassium humate and nitrogen fertilizer on herb and essential oil of oregano under different irrigation intervals, J Appl Sci., 2009, 2, 319-323.

26-S.F. Hendawy, K.A. Khalid, Effect of chemical and organic fertilizers on yield and essential oil of chamomile flower heads, Med Aromat Plant Sci Biotechnol, 2011, 5, 43-48.

27-T. Zair, S. Khannouchi, F. Elhilali, Biocidal effects of aqueous extract of the roots of Anacyclus pyrethrum (Asteraceae) on Callosobruchus maculatus (Fab.) (Coleoptera: Bruchidae), Mediterr. J. Chem., 2012, 1(6), 316-325.

28-F. Remok, Y. Ait Aicha, S. Khannouchi, T. Zair, Phytochemical and biological studies of Anacyclus pyrethrum L, International Colloquium on Valorization of natural and synthetic biomolecules in Novel drug-vector nanostructures, 15, 16 April 2019, p52.

29-G. Aćimović, V. Tešević, M. Todosijević, I. Oljača, K. Dolijanović, Essential oil content and composition of aniseed, J Nat Sci Res., 2015, (128), 67-75.

30-A. Orava, A. Raalb, E. Arakb, M. Müüriseppa, T. Kailasa, Composition of the essential oil of Artemisia absinthium L. of different geographical origin, J Proc Estonian Acad Sci Chem., 2006, 55(3), 155-165.

31-A. Mambrí, J. Andriolo, M. Manfron, S. Pinheiro, F. Cardoso, M. Neves, Yield and composition of lavender essential oil grown in substrate, Hortic Bras, 2018, 36(2), 259-264.

32-K. Norajit, N. Laohakunjit, O. Kerdchoechuen, Antibacterial effect of five Zingiberaceae essential oils, Molecules, 2007, 12(8), 2047-2060.

33-H. Baydar, O. Sagdic, G. Ozkan, T. Karadogan, Antibacterial activity and composition of essential oils from Origanum, Thymbra and Satureja species with commercial importance in Turkey, Food Control, 2004, 15(3), 169-172.

34-H. Fodil, M. Sarri, N. Hendel, F. Maggi, D. Sarri, Essential oil composition of aerial parts from Algerian Anacyclus monanthos subsp. cyrtolepidioides (pomel) humphries, Nat Prod Res., 2019, 33(2), 292-295.

35-A.R. Dashipour, M. Reza, Shahraki, J. Dehvari , M. Shahrakipoor, E. Shahreki, A. Sharaki, The effects of Anacyclus pyrethrum alcoholic root extract on FSH, LH, testosterone and sperm count in diabetic male rats, J Med Sci., 2019, 21(2).

36-R. Pavela, P. Sedlák, Post-application temperature as a factor influencing the insecticidal activity of essential oil from Thymus vulgaris, Ind Crops Prod., 2018, 113, 46-49.

37-R. Pavela, Acute, synergistic and antagonistic effects of some aromatic compounds on the Spodoptera littoralis Boisd. (Lep, Noctuidae) larvae, Ind Crops Prod., 2014, 60, 247-258.

38-D. Annik Boussou, S. Mangelinckx, H. Yedmonhan, P. Boko, M. Akogbeto, N.D. Kimpe, F. Avlessi, D.C.K. Sohounhloue, Chemical composition and insecticidal activity of plant essential oils from Benin against Anopheles 
gambiae (Giles), Parasit Vectors, 2013, 6(337). https://doi.org/10.1186/1756-3305-6-337.

39- A. Urzúa, R. Santander, J. Echeverria, N. Cabezas, S.M. Palacios, Y. Rossi, Insecticide Properties of the Essential Oils from Haplopappus foliosus and Bahia ambrosoides Against the House Fly, Musca domestica L, Chil Chem Soc., 2010, 55(3), 1-5.

40-S.D.G. Aciole, C.F. Piccoli, J.E. Duque, E.V. Costa, M.A. Navarro-Silva, F.A. Marques, B. H. Sales Maia, M.L.B. Pinheiro, M.T. Rebelo, Insecticidal activity of three species of Guatteria (Annonaceae) against Aedes aegypti (Diptera: Culicidae), Rev Colomb Entomol., 2011, 37(2), 262-268.

41-R. Pavela, Insecticidal properties of Pimpinella anisum essential oils against the Culex quinquefasciatus and the non-target organism Daphnia magna, Asia-Pac Entomol., 2014, 14, 287-293.

42-H. Vatandoost, D.A. Sanei Dehkordi, S.M.T. Sadeghi, B. Davari, F. Karimian, M.R. Abai, M.M. Sedaghat, Identification of chemical constituents and larvicidal activity of Kelussia odoratissima mozaffarian essential oil against two mosquito vectors Anopheles stephensi and Culex pipiens (Diptera: Culicidae), Exp parasitol, 2012, 132(4), 470-474.
43-F. Tine-Djebbar, D. Dris, H. Bouabida, N. Soltani, Chemical composition and activity of an Ocimum basilicum essential oil on Culex pipiens larvae: Toxicological, biometrical and biochemical aspects, S Afr J Bot., 2017, 113, 362-369.

44- A. Ali, N. Tabanca, B. Demirci, E.K. Blythe, Z. Ali, K.H. Baser, I.A. Khan, Chemical composition and biological activity of four salvia essential oils and individual compounds against two species of mosquitoes, J Agric Food Chem., 2015, 63(2), 447-56.

45-M. Govindarajan, M. Rajeswary, G. Benelli, Chemical composition, toxicity and non-target effects of Pinus kesiya essential oil: An ecofriendly and novel larvicide against malaria, dengue and lymphatic filariasis mosquito vectors, Ecotoxicol Environ Saf., 2016, 129, 85-90.

46-M. França, O. M. Breda, R.S. B. Douglas, A.M. N. Araujo, C.A. Guedes, The sublethal effects of insecticides in insects, 2017. http://dx.doi.org/10.5772/66461.

47-B. Naseri, Z. Abedi, A. Abdolmaleki, M. JafaryJahed, E. Borzoui, M. Mansouri, Fumigant toxicity and sublethal effects of Artemisia khorassanica and Artemisia sieberi on Sitotroga cerealella (Lepidoptera: Gelechiidae), J Insect Sci., 2017, 17(5), 1-19. 